\title{
The acquisition of autonomy, through benevolence, of children who are victims of domestic violence
}

\author{
Priscelle Andeme Ngui Valandro', Loïc Chalmel ${ }^{2}$
}

\begin{abstract}
From its etymology bene (good) and volens (will), benevolence means desire to do well. Benevolence is not an arbitrary notion or a theoretical apprehension. It unquestionably reveals man's humanism, which must combine in its daily practice and management with his fellow human beings and even with himself. In education, benevolence is crucial in mother-child relations. We believe that a mother must be benevolent, at the same time as; a child who has received the love of his mother (or parents) can love himself. This is a prerequisite for the acquisition of independent thought. The true cement of any family unit is the mutual love of all those who are called to live together. Paradoxically, love is not the foundation of all families. Unfortunately, there are dysfunctional families in which there are various and varied forms of violence. Children from this type of environment find themselves victims of abuse with all the possible traumatic consequences. Based on this observation, it is easy to reason by deduction: if family love conditions the acquisition of autonomy and children who are victims of family violence do not benefit from it within their families, then children who are victims of family violence are at a disadvantage in acquiring autonomy, or even that they cannot be autonomous. Thus, one may wonder to bring a child victim of family violence to the acquisition of his autonomy? What tools can be used to help a traumatized child become autonomous? How to rebuild a child who has suffered family trauma with a view to his or her autonomy? This article offers the reader benevolence, not as an instruction manual or prescription to be applied, but as a transferable and impactable posture.
\end{abstract}

\section{Article History}

Received: 17 February 2021

Accepted: 22 June 2021

Keywords

Autonomy; Benevolence;

Naive transfer; Child victim

of domestic violence

\section{Introduction}

Whatever the type of family -sociological, poly or monogamous, endogamous, exogamous, tribal, nuclear, homoparental- the reader of this article will recognize that the family is a rather difficult institution to define. Summarizing the definition of the dictionary Le Petit Larousse Illustré (Famille, 2002, p. 420): “all persons of the same blood, living under the same roof and more particularly the father, mother and children". Poirot (1973) speaks of coexistence under the same roof and the blood ties of people. At the same time as for him, these two criteria are insufficient for coexistence; he posits love as the driving force for the coexistence of parents and children within a family. However, there is unfortunately another reality contrary to the criterion of love that should govern a family: violence within families. Among the types of families, there are so-called dysfunctional families. Within this type of family, there are various forms of violence: conjugal, physical, psychological, sexual, abandonment, rejection, parentification. The readings indicate that the family context in which a child evolves, has a profound impact on his health and wellbeing - being because of reproduction or imitation. This is to say that this violence alters the psychological development of child victims. The child's " $\mathrm{I}$ " is then shattered because of traumas suffered. However, Hoffmans - Gosset (2002, p. 27) mentions the importance of the "I" as subject and actor in the acquisition of autonomy. At this level, we then find ourselves confronted with a problem that brings us face to face

${ }^{1}$ LISEC Laboratory, Department of Educational Science, University of Haute Alsace, 11 rue des frères lumière, 68100 Mulhouse, France, e-mail: v.priscelle@yahoo.fr. ORCID: https://orcid.org/0000-0001-6092-8474

2 LISEC Laboratory, Department of Educational Science, University of Haute Alsace, 11 rue des frères lumière, 68100 Mulhouse, France, e-mail: loic.chalmel@uha.fr. ORCID: https://orcid.org/0000-0003-4449-608X 
with an " $\mathrm{I}$ " shattered by the traumas on the one hand. On the other hand, the same " $\mathrm{I}$ " is strongly solicited to acquire autonomy.

In order to get out of this dilemma that puts the child's "I" in a dualistic position, this article puts at the heart of both portraits the benevolent impulse that propels towards autonomy. It is structured in two parts. First, we will see theoretically how by a benevolent posture one transfers autonomy. Then we will see in a practical way the feasibility of our reflection through a methodology that we propose. The posture of any researcher begins with a questioning. Let us take up again the questioning that guides our work: How to bring a child victim of domestic violence to the acquisition of his autonomy? By which tool can a traumatized child become autonomous? How to rebuild a child who has suffered family traumas for his autonomy? To answer this question which is the subject of our research, we postulate that it is possible for a child shattered by family violence to rebuild his or her autonomy through the phenomenon of reproduction and transfer of benevolence or by imitating the benevolence of the guardian who accompanies the child victim of family violence, without necessarily making the child fall into a form of dependence on his or her guardian. In order to test our hypothesis, let us first define and circumscribe the field of autonomy.

The rest of this paper is organized as follows: the first part deals with the theoretical construction in which the child victims of domestic violence and their consequences are first examined, the second part includes a definition and circumscription of field autonomy. In the following, the "I" heteronomy of the child victim of domestic violence is presented followed by the benevolence: Carl Ransom (1902-1987) then the benevolent and autonomous "I" of the guardian and finally the heteronomy to autonomy through the pedagogy of naive transfer. The second part is devoted to an example of the theoretical construction in which the natural method of transfer: from the bottom up is presented and the placement chart of the child by the transfer of the bottom - up naive is established. The conclusion is presented at the end of the paper and summarizes the salient points.

\section{Theoretical Construction}

\section{Children Who Are Victims of Domestic Violence and The Consequences}

For Bovay (2008) quoted in Valandro and Chalmel (2020, p. 3), "violence refers to physical behavior and actions: it consists of the use of force against someone with the damage it causes". Valandro and Chalmel (2020) write that a child who is a victim of domestic violence is a child to whom his or her family system offers conditions of survival and not of life, moreover, interspersed with violence. These include physical, psychological, sexual, abandonment, rejection, parentification...and many other forms of child abuse within the family. Cudré-Mauraux (2012) recognizes that psychological violence: verbal aggression (threats, insults...) attacks psychological integrity. Savard and Zaouche (2011) point out that exposing children to physical violence leads to disorganization in the child's life. Note also that children's exposure to violence has traumatic consequences Valandro and Chalmel (2020). Cyrulnik and Jorland (2012, p. 175) defines psychological trauma as all the psychological and physiological damage resulting from an event suffered, where any form of violence experienced physically or morally varies individually, being linked to personal history.

\section{Autonomy: Define and Circumscribe the Field}

The word autonomy comes from the Greek word autonomia, which means the power of one who is autonomos, that is to say, who determines for himself the law (nomos) to which he obeys. For Lafon 1905 -1980) quoted by Hoffmans - Gosset (2002, p. 15), autonomy consists in making oneself - even one's own law and self-determination in values. The "I" is the principle of autonomy and we can only speak of autonomy when there is self-awareness. Connac (2017) even evokes different types of autonomy: functional, moral, legal and intellectual. As for our work, we will follow in the footsteps of Hoffmans Gosset (2002, p. 30) and speak of affective autonomy. Hoffmans - Gosset (2002) explains in this regard that this type of autonomy is translated into being, that is to say that it is a state, it is experienced bodily, it is valued and is gratifying. She writes clearly that "a pleasant, satisfying state seems to come from a practice 
of autonomy". In order for autonomy to exist, it must be experienced, it cannot be given just as one cannot speak of someone else's autonomy when one is in the order of affectivity. Autonomy touches something in us in the order of vitality and survival. It explains that it cannot be given as a manual, in which case it is no longer autonomy. And the person claiming it is not an autonomous person.

\section{The "Me" Heteronomy of The Child Victim of Domestic Violence}

To understand this logic of Hoffmans - Gosset (2002), affective autonomy is an evolutionary construction. It is constructed, in the same way as the "me" is constructed. It must be built within a framework that is empowering or favorable to the construction of identity. Let us specify that the empowering environment is an environment that offers an affective basis to a child for his identity construction and development. With this in mind, we call again on the reader of this work to remind $\mathrm{him} /$ her of the living conditions of a child victim of family violence. He/she (reader) will recognize that the family is supposed to be a favorable environment for the construction of identity. However, we are in the sad reality that the family is not an enabling environment for the construction of the autonomy of a child victim of family violence due to a lack of affectivity. In the same way that the child's "I" has not been built, his autonomy has not been built either. Fortin (2010), and even Cyrulnik (2017) show that the environment has a strong impact on the child's entire personality. The more favorable this environment is, the more stable and constructed the child is. It conditions the child's education and autonomy. However, for Connac (2017), heteronomy is a constraint which consists in acting under the law of another, the will is determined by an external object. It results in the exercise of submission (whether consensual or not) to a power and leads to forms of assistance where the commitment is triggered by constraint or an external impulse. This "I" is opposed to any logic of autonomy as we have developed it.

\section{Benevolence: Carl Ransom (1902-1987)}

In this paper, we choose to refer to the philosopher Carl Ransom and to treat benevolence from an educational perspective. He speaks synonymously of empathy to bridge the gap between psychology and pedagogy. It (benevolence) calls upon human sensitivity, humanism towards others and a spirit of openness towards others. In the same spirit, the psychologist Carl Ransom (1995, p. 21), taken up by Chalmel (2018), places empathy at the crossroads between Christianity and psychology. He therefore uses the same terms such as "to feel the emotions of the student, to share his feelings..." Chalmel (2018). He goes on to say that in education, the concept of empathy does not take shape if the teacher initially examines himself and his examination is confined to his repeated questions Chalmel (2018): Am I authentic and am I aware of who I am? Am I capable of positive relationships? Do I have the strength to be distinct from the other? Do I have enough inner security to leave the other free? The interest of these questions lies in the thinking subject: the teacher, whom we call the child's companion. From his reflection emerges his posture, his way of being which must be based on what he embodies and on what he is. We would even say that he must be confident in what he is. In this regard, Chalmel (2018) specifies that "tutoring is based on trust. Any other constraint produces mistrust".

\section{The Benevolent and Autonomous "Me" of the Guardian}

The guardian, which we develop in this article, is the one who does what he says, who is what he says. He is the one whose discourse is the practice, a coherent tutor. His behavior must bear witness to the responsibility of the one who carries out his work as a tutor. Freire's $(2006$, p. 80) requirement of teachers is such that he writes: "If one cannot expect his agents to be angels and saints, one can and must nevertheless demand from them righteousness and a serious attitude". In fact, when we read Paulo Freire's Pedagogy of Autonomy (2006) which is a key book on the acquisition of autonomy, we come across a strong anaphoric repetition of the verb "to demand", evoking the different attributes of the teacher. He writes, for example, that "Teaching requires humility..." Freire (2006, p. 81). Also, he writes: "Teaching requires joy and hope", Freire (2006, p. 86). The verb "to demand" challenges us in such a way that it must be an ethically imposable posture. This demand is the one we want to transfer to the guardian of benevolence with regard to a child who is a victim of domestic violence. 


\section{From Heteronomy to Autonomy: Through the Pedagogy of Naive Transfer}

For professional training, we based to the inspiration of the pedagogue Paulo Freire, we allow ourselves to establish the naive transfer as a suitable method to accompany a child victim of domestic violence towards his autonomy, or at least to build the autonomy of a child victim of domestic violence. This naive transfer is built around an ethical positioning in which we situate this article. Indeed, Freire (2017, p. 48) speaks of epistemological knowledge and naive knowledge. He explains that naive knowledge is made up of pure experiences and attributes it to the curiosity of analgabetes persons. Moreover, there is no break between naïve knowledge and epistemological knowledge. We want to highlight the fact that the transfer that is going to take place will be a transfer based on imitation of the behavior of the tutor supervising the child.

\section{Stakes of The Pedagogy of Naive Transfer}

Through this model of accompaniment by transfer of naive knowledge, we want to highlight the posture of the accompanier of a child who has suffered trauma within his family. This pedagogy is built around two instances, the "me" of the tutor and the "me" of the child. The pedagogical action is only the tutor's "me": all that it is and embodies as values. The "me" of the oppressed is invaded by the shadow of the oppressor; the oppressed has the duty to expel this shadow and replace it with his or her autonomy. Through this pedagogy, we want to invite the transmitting "me" to incarnate the values it claims to embody so that through its behavior, its teaching will echo. The heteronomous "me" of the child is influenced by outsiders. In order for this child's "self" to become autonomous, he will simply have to imitate his tutor. Therefore, the tutor must embody a good posture so that the child imitates him in a natural way. The tutor therefore does not need to teach the child autonomy as a lesson to be studied. The tutor must be natural to transmit his natural posture to the child. Clearly, we situate this passage in the paradigm of "such I am and such you must be". Given that "imitation is the fundamental conduct by which the child accomplishes his conquests", Nadel and Zazzo (1986, p. 21). Naive transference is a natural method that makes practical use of the guardian's posture. The child's "me" will be imitated.

\section{Example of the Theoretical Construction}

We believe that all scientific reflection should aim at a plan for putting the theory developed into practice. This step is only the feasible or living part of the ideas developed. Moreover, in his praxeological approach Freire (2006, p. 48) clearly writes that "Critical reflection on practice becomes a requirement of the theory/practice relationship, without which theory can turn into blah-blah, and practice into activism". Thus, in our work, we have thought about the autonomy of a child victim of domestic violence. We propose, as a practical example, a type of accompaniment towards the construction of the autonomy of this type of child. For this accompaniment, the tutor in charge of the child's care must embody a posture, the said posture will be transferred to the child by what we have called: the pedagogy of naive transfer. That is to say, from the autonomous "I" of the tutor to a heteronomous "I" of the child, this heteronomous "I" which, by imitating the values of the tutor, will become autonomous.

\section{Natural Method of Transfer: Bottom Up}

The naive transfer pedagogy that we have developed in our theoretical approach will be confined to what we will call in our methodology the "bottom up" approach.

\section{Definition}

Bottom-up is an ascending approach (from the bottom to the top) that will bring out theories of practice. Our theories put us in front of two instances: a shattered and heteronomous "me". This "me", in our methodology, will be identified with the position of the bottom, because of its lack of autonomy following the various traumas it has undergone. We recognize that this unfulfilled instance is the "me" of the child victim. The second instance of our theories is also an "me" that opposes the unfulfilled "me". This "I" is that of the guardian, benevolent and autonomous. In our bottom-up method, the autonomous "me" of the guardian occupies the position of the top. This high position is recognized because of its construction, 
The acquisition of autonomy, through benevolence, of children...

its autonomy and its benevolence. The bottom-up methodology, as we conceive it, is unconscious or naive because of the type of transference we have evoked in our theories. Let us acknowledge, however, that this method is inspired by the pedagogical experience developed by Pestalozzi (1799) in Neuhoff and quoted in Lettre de Stans (1996, p.30).

Indeed, the pedagogue opens an institute that takes care of orphans, the poorest and most abandoned children. For these little orphans he opts for a purely family approach, from which he believes that "Every good education requires that the strength of the educator be no other than that of a father, animated by the presence of all the circumstances of domestic life", Pestalozzi (1985, p. 18). His method is based only on the benevolence he intends to transmit to this public. "My way of proceeding in this regard was based on the following principle: seek first to enlarge the hearts of your children and to bring their sensitivity, experience and activity into contact with love and benevolence...", Pestalozzi (1985, p. 30). In the pedagogue's approach, two important things attract us: the creation of a family context and benevolence as a pedagogical tool for the acquisition of autonomy. Also, in Pestalozzi's experience, children, whose "I" is completely destroyed, were asked to rebuild themselves according to the Pestalozzi model itself. In this approach, we find the bottom-up method of unconscious transference which is the basis of this part of the work.

In concrete terms, there is talk of setting up a type of care for children who are victims of domestic violence within a caring family.

\section{Placement Chart of The Child by The Transfer of the Bottom - Up Naïve Method}

Table 1 shows the transfer of the child from two institutions: from an institution in his or her biological family environment to a foster family. The placement is subject to legal proceedings following a report. With regard to the child's problems, the choice of foster family is based on a family composition close to the child's family. The main objective is to enable the child to build his or her emotional autonomy. This can be verified when the child unconsciously inspires the adoptive parents to set up a support program for his or her follow-up. In other words, through observation in gestures, words...the child will express desires about his activities. These desires will be studied and analyzed by the tutors, who will judge by this language a certain freedom of the child to build himself and be autonomous. "Respect for the autonomy and dignity of each person is an ethical imperative and not a favour that we may or may not grant to one another", Freire (2006, p. 75)

It should be noted that guardians do not coerce the child in any way. They leave him a certain freedom of action with, of course, advice, guidance, guidance, adjustments, to avoid falling into the trap of letting him go. They live with the child as they are.

Table 1. Table of placement chart of the child by the transfer of the bottom - up naive

\begin{tabular}{|c|c|c|}
\hline & Child & Family \\
\hline Institution & Legal Placement at Home & Is selected by the juvenile judge \\
\hline Criteria & $\begin{array}{l}\text { Non-autonomous } \\
\text { From a dysfunctional family }\end{array}$ & $\begin{array}{l}\text { Capable of operating autonomously. } \\
\text { Caring. } \\
\text { Stable. } \\
\end{array}$ \\
\hline Type & 10 to 15 years & $\begin{array}{l}\text { Identical to the composition of the } \\
\text { biological family. }\end{array}$ \\
\hline Objectives & $\begin{array}{c}\text { 1/ At the end of the stay, the child must be able to } \\
\text { demonstrate independence in daily activities. } \\
\text { 2/Express your wishes and desires gradually, freely and } \\
\text { unconsciously }\end{array}$ & $\begin{array}{l}\text { to lead the child to build his autonomy. } \\
\text { Translate the child's requests into a support } \\
\text { tool. }\end{array}$ \\
\hline Methodology & $\begin{array}{l}\text { Bottom up (Imitation) } \\
\text { Pedagogy of freedom }\end{array}$ & Bottom up by naive transfer \\
\hline Requirements & & $\begin{array}{c}\text { Orientation-Adjustment - Freedom to } \\
\text { behave }\end{array}$ \\
\hline
\end{tabular}




\section{Conclusion}

The work we have done is aimed at two very important players. On the one hand, a person, or at least a child, who is a victim of violence and who wants to rebuild his or her life. And on the other hand, a tutor to accompany them towards reconstruction. It presents benevolence as a tool for acquiring autonomy. He opts for a transfer of benevolence in a natural way: from a "senior "I" benevolent" to a "Junior "I" benevolent". With all that we have developed, it is possible that the autonomous benevolent being creates autonomy through human contact.

The reader of this article will have quickly understood the positioning or ethical dimension in which we situate our work. Or better still, he or she will have understood the challenge or awareness of the values that underpin human dignity, which are at the heart of everything we have developed. The discerning reader will have quickly understood that there is a pressing challenge to benevolence for any accompanying tutor. This article advocates an embodiment of benevolence that goes beyond professional constraints. The reflection we have conducted also invites professional actors in caring for people who want to be part of a neo development process to a critical examination of their values. Far from being a work of accusation, our work makes a point of saluting the nobility and humanity of their profession and also saluting the efforts they make to reintegrate others into a beautiful life expectancy.

\section{Declarations}

Acknowledgements: Not applicable.

Authors' contributions: The authors declare that they have equally contribution.

Competing interests: The author declares that they have no competing interests.

Funding: This work was not supported by any funding.

\section{References}

Chalmel, L. (2018). De la bienveillance en éducation. Évolution historique d'un concept et des pratiques associées. Questions Vives. Recherches en Éducation, 29, 1-14.

Connac, S. (2017). Teaching without excluding. Pedagogy of the Hummingbird. Paris, France: Esf éditeur.

Cudré-Mauroux, A. (2010). Le personnel éducatif face aux comportements-défis: implication de l'attribution causale et expression du sentiment d'efficacité personnelle dans le processus de stress transactionnel. (Thèse de doctorat, Université de Fribourg - Suisse). Repéré à https://edudoc.ch/record/87081/files/?ln=fr.

Cyrulnik, B. (2017 décembre). Le récit de soi. Mulhouse, France. Communication Présentée À La Conférence Du 10ème Anniversaire du Programme de Réussite Educative.

Cyrulnik, B., \& Jorland, G. (2012). Résilience et connaissances de base. Paris: Odile Jacob.

Famille (2002). Le petit larousse illustré. Paris: Larousse-Vuef.

Fortin, A. (2010). Le développement du lexique et l'aide aux apprentissages. Enfances \& Psy, 2(2), 30-41.

Freire, P. (2006). Pédagogie de l'autonomie. Toulouse: Erès.

Freire, P. (2017). Pédagogie de l'autonomie. Toulouse: Erès.

Hoffmans - Gosset, M. A. (2002). Learning autonomy. Learning socialization. Lyon: Social Chronicle.

Nadel, J., \& Zazzo, R. (1986). Imitation and communication among young children. Paris: PUF.

Pestalozzi, H. (1985). Letter from Stans. Paris: Mini Zoé.

Pestalozzi, H. (1996). Lettre de Stans. Paris: Mini Zoé.

Poirot, M. (1973). L'enfant et les relations familiales. Paris: FeniXX Presse Universitaire de France.

Rogers, C., R. (1995). A way of being. New York: Houghton. Mifflin Harcourt

Savard, N., \& Zaouche - Gaudron, C. (2011). Point de repères pour examiner le développement de l'enfant exposé aux violences Conjugales. La Revue İnternationale de L'éducation Familiale, 29, 13-35.

Valandro, P. A. N., \& Chalmel, L. (2020). Emotional detachment-resilient space: Child in family difficulty. European Journal of Education Studies, 7(1), 62-71. 